\title{
TRACTOR MFWD BRAKING DECELERATION RESEARCH BETWEEN DIFFERENT WHEEL DRIVE
}

\author{
Povilas Gurevicius, Algirdas Janulevicius \\ Aleksandras Stulginskis University, Lithuania \\ povilasgurevicius@asu.lt, algirdas.janulevicius@asu.lt
}

\begin{abstract}
The article presents and analyses the reasons of the braking parameter in $4 \times 4$ tractor. It is noted that the wheeled tractors are working in transport, cargo, driving with implements and without them in the fields, etc. for most of the time. The contact area with the road surface during braking decreases when increasing the driving speed and the overall dynamic stiffness of the tire changing increases the rolling resistance. However, it is worth mentioning that the tire contact with the road surface area is also dependent on the tire air pressure and improperly selected or uneven tire air pressure to increase the vehicle rolling resistance, increasing the frontwheel lead, which reduces the braking efficiency. The change of the front-wheel lead increases kinematic discrepancy between the drive wheels. These factors have negative effect for the tractor performance parameters, the transmission is loaded heavily, the power losses are increased, tires wear faster, the fuel consumption is increased. This article shows and analyses tractor deceleration between different wheel drive $(4 \times 2$ and $4 \times 4)$ with different driving speed.
\end{abstract}

Keywords: inflation pressure, deceleration, braking, agricultural tractor.

\section{Introduction}

Tractors are identified as MFWD (Mechanical Front-Wheel Drive) tractors, when the front axle is driven by a mechanical drive and the front drive wheels are smaller than the rear wheels. Today, MFWD tractors are extensively used for transportation work when connected to the tractor trailer or semi-trailer. The latter considerably increases the tractor rear wheel vertical load and the rear tire deformation, but reduces the front-wheel vertical load and tire deformation. Increasing and decreasing the rear of the front tire deformation increases the actual size of the front wheel advance. This change has no harmful effects on the tractor vehicle dynamics while working, because when running a good road and at higher speed, the front wheel drive is generally unplugged. However, front-wheel accelerates change effects of the MFWD tractor braking dynamics, since the braking front axle is always automatically enabled [1-4].

Brake and steering systems in vehicles are the most effective gear, which directly affects the vehicle dynamics. In general, the brake system is running in the longitudinal vehicle dynamics and driving dynamics system running side. However, their effects combine when the vehicle is braked on uneven surfaces. The yaw moment braking compensates for steering control on the road. To avoid improper steering compensation vehicles have been equipped with the wheels being driven in rotation angle of the controller, designed to mitigate the impact of asymmetric braking forces and stabilize the angular deviation in vehicles [5-7].

Freight transportation tractors are combined with various trailers or semi-trailers. Almost $75 \%$ of kinetic energy of the tractor-trailer combination is acquired from the trailer, so it is very important that the brake system of the trailer is sufficient to defeat the emerging kinetic energy. The stability of the compound depends on the coordination of the tractor and trailer braking systems, and also their braking efficiency. If the tractor brake system works better than the trailer brake system, the braked tractor can be pushed, and the tractor is pulled, the trail braking efficiency is better. The braking process is the best when the tractor-trailer brake efficiency is the same $[4 ; 8 ; 9]$.

The necessity to use the brake system can occur in various situations. However, all braking systems are divided into two categories [10]:

1) emergency braking, corresponding to a maximum possible braking intensity;

2) operational or partial braking.

The maximum braking force developed by the vehicle wheel depends on the wheel grip to the road and vertical road reaction affecting the wheel. Operational braking intensity is always less than the maximum possible braking efficiency. Emergency braking does not exceed 5-10\% of all braking situations. However, this is a very important condition, which is important in emergency situations. 
This is the reason why all the rules and regulations related to the braking efficiency of the system are set up in the emergency braking system $[5 ; 8 ; 9]$.

Generally, the following actuating forces reduce the tractor speed [10; 11]: braking; rolling resistance; air resistance; friction bearings.

The value of braking forces, under the conditions of braking of maximum intensity, represents $98 \%$ of the total forces that reduce the speed of vehicles [12, 13].

When stopping the tractor to exploit the full weight of it, grouped by pressing the brake pedals, automatically turning on the front wheel drive, the front and rear drive axle kinematic coupling of all wheels is used. For this reason, the tractor $4 \times 4$ braking dynamics are inseparable from the driving wheel kinematic discrepancy $[2 ; 3 ; 11]$.

The goal of this analysis is to find the kinematic discrepancy influence for all-wheel drive tractor deceleration.

\section{Materials and methods}

By changing the air pressure of the tractor wheel drives, their deformities also change. Disproportionate deformations of the front and rear wheels change the all-wheel drive tractor kinematic discrepancy size. The main goal of this research is to find the tractor braking parameter generated by tire air pressure regulating, variation limits and the driving speed.

The main technical data of the tractor used in the experiments are shown in Table 1.

Technical data of tractor

Table 1

\begin{tabular}{|c|c|}
\hline Technical data & CASE IH Farmall U Pro 115 \\
\hline Rated engine power, $\mathrm{kW}$ & 114 \\
\hline Rated engine speed, $\mathrm{rpm}$ & 2200 \\
\hline Weight of the tractor, $\mathrm{kg}$ & 4900 \\
\hline Wheelbase, $\mathrm{mm}$ & 2420 \\
\hline Front tires & Trelleborg 480/65 R24 \\
\hline Rear tires & Trelleborg 540/65 R38 \\
\hline Weight of the front axle, $\mathrm{kg}$ & 2004 \\
\hline Weight of the rear axle, $\mathrm{kg}$ & 2896 \\
\hline Recommendations front tires pressure, $\mathrm{kPa}$ & $160-190$ \\
\hline Recommendations rear tires pressure, $\mathrm{kPa}$ & $120-150$ \\
\hline
\end{tabular}

The tractor deceleration, braking distance, time and tire pressure of the front and rear driving wheels were measured in the research.

Investigations were carried out with the tractor reaching $10 \mathrm{~km} \cdot \mathrm{h}^{-1}$ and $20 \mathrm{~km} \cdot \mathrm{h}^{-1}$, the maximum (emergency) braking.

The weather conditions were: temperature $14{ }^{\circ} \mathrm{C}$, wind speed $4 \mathrm{~km} \cdot \mathrm{h}^{-1}$ and humidity $81 \%$.

All wheel drive tractor kinematic discrepancy and braking parameter dependence on the tire air pressure research was made with the following combinations $(230 / 80,230 / 130,230 / 180,230 / 230$, $180 / 230,130 / 230,80 / 230 \mathrm{kPa}$ ) in the tractor front and rear tires. All researches were made with the front drive turned on and turned off, riding on the same segment, same direction with different driving speed. Tests were made on a hard road surface, on horizontal, straight road. For distance measuring we used Measi S3a measurement device with measurement error of $\pm 1.5 \mathrm{~mm}$. For deceleration measuring we used AccDriver 211 device (Fig. 1), which is mounted on the tractor Case IH Farmall.

The device was activated prior to the test. During the test, the tractor braking device automatically shows acceleration and deceleration of the tractor. When starting to stop, the device activation is not required. The device AccDriver 211 has a built-in memory and stores the test data automatically.

The technical parameters are presented in Table 2. 


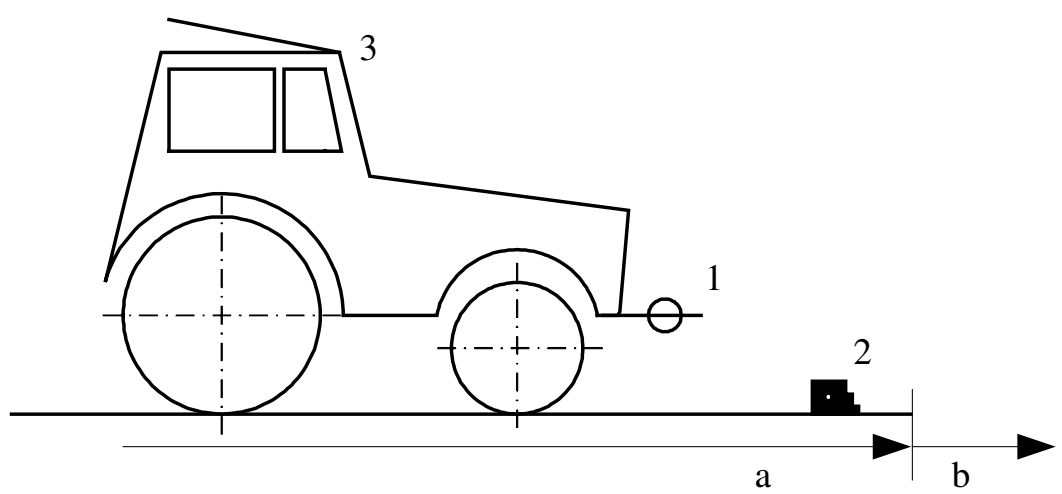

Fig. 1. Research scheme: 1 - distance indicator; 2 - marked line; 3 -deceleration measurement device; $\mathrm{a}$ - tractor acceleration zones; $\mathrm{b}$ - tractor braking zones

Table 2

Acceleration measurement device AccDriver 211 technical specification

\begin{tabular}{|l|c|}
\hline \multicolumn{1}{|c|}{ Technical data } & AccDriver 211 \\
\hline Size & $105 \times 65 \times 20 \mathrm{~mm}$ \\
\hline Screen & $132 \times 32 \mathrm{point}$ \\
\hline Acceleration measurement range & $\pm 2 \mathrm{~g}\left( \pm 20 \mathrm{~m} \cdot \mathrm{s}^{-2}\right)$ \\
\hline Acceleration measurement accuracy $\left(\right.$ when $\left.25^{\circ} \mathrm{C}\right)$ & $0.04 \mathrm{~m} \cdot \mathrm{s}^{-2}$ \\
\hline Weight & $<100 \mathrm{~g}$ \\
\hline
\end{tabular}

In order to have more accurate results all tests were repeated 3 times.

Kinematic discrepancy was calculated by all-wheel drive tractor front and rear wheel slippage rates; the formula is shown below:

$$
k_{n}=\frac{1-\delta_{r}}{1-\delta_{f}},
$$

where $\delta_{r}$ and $\delta_{f}$ - slippage (or sliding - when the result was obtained with a minus sign) of the front and rear driving wheels;

The tractor front and rear wheels factor of slippage was calculated by the given formula:

$$
\delta=\frac{s_{t}-s_{a}}{s_{t}},
$$

where $s_{t}$ and $s_{a}-$ theoretical and actual wheel distances for 10 wheel rolls.

During the tests, the distances were measured by how far each of the front and rear wheels travelled during 10 rolls. Markers were attached to the front and rear wheels and marks were made on the road for the distances that both front and rear wheel travelled. The theoretical distance, according to the American Society of Agricultural Engineers (ASAE) standard S296.2, is the distance travelled per roll of the wheel when operating at the specified zero condition [14].

In this research the specified zero condition has been given when the tractor front drive was turned off.

\section{Results and discussion}

With the tractor $4 \times 4$ moving with enabled front axle drive, in many cases there are kinematic discrepancies between the front and rear wheel theoretical speeds. A change in the air pressure in the front and rear tires changes the kinematic discrepancies. Once the tractor is unloaded from pull or push forces, kinematic discrepancies make one wheel to slip, while the other to skid.

Kinematic discrepancy values of tire pressure are shown in Fig. 2. 


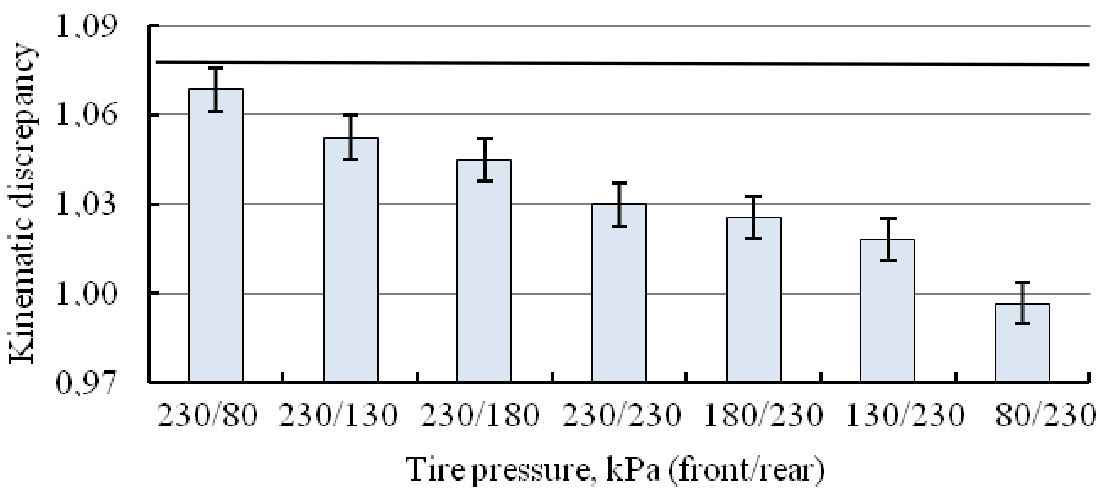

Fig. 2. Kinematic discrepancy coefficient values for different front and rear tire pressures: $\mathrm{LSD}=0.013$

One-way analysis of variance (ANOVA) was performed with MS Excel to analyse the data. Significant difference between different tire pressure control systems was determined with the Fisher's least significant difference (LSD) range test $(p<0.05)$.

Fig. 2 shows that the kinematic discrepancy rate had been in the tractor manufacturers and other researchers recommended range (around 1) when the pressure in the front tires was $80 \mathrm{kPa}$ while in the rear it was $230 \mathrm{kPa}$. It can also be seen that during rides with almost all tire pressure combinations in the front/rear tires except $80 / 230 \mathrm{kPa}$, the kinematic discrepancy coefficient was higher than 1 . In order to have lower kinematic discrepancy on asphalt surface, it is recommended to use higher inflation pressure in the rear tires and lower inflation pressure in the front tires.

Figures 3 and 4 present tractor deceleration dependence on the driving speed with the highest (Fig. 3) and the lowest (Fig. 4) kinematic discrepancy.

It can be seen that increasing the kinematic discrepancy the tractor deceleration threshold between the minimum and maximum values increases. At maximum kinematic discrepancy, when the tractor is driving at the speed of $10 \mathrm{~km} \cdot \mathrm{h}^{-1}$ and has an enabled front axle $(4 \times 4)$, the maximum braking acceleration changes from -5.97 to $-0.09 \mathrm{~m} \cdot \mathrm{s}^{-2}$. The minimum kinematic discrepancy coefficient changes from -5.12 to $-1.67 \mathrm{~m} \cdot \mathrm{s}^{-2}$.

According to Figures 3 and 4, it can be stated that depending on the number of wheels involved in braking $(4 \times 2$ or $4 \times 4)$, the tractor deceleration was greater and there was less stopping time when the front axle was turned.

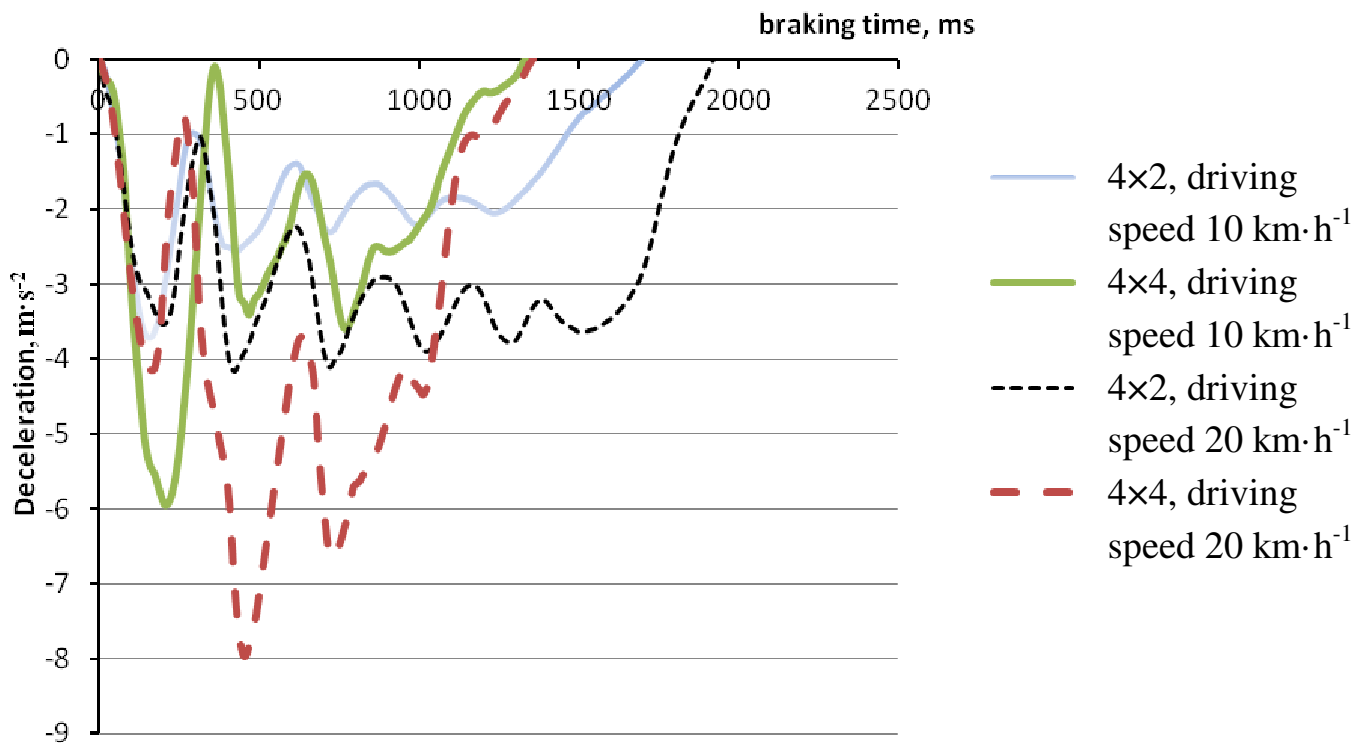

Fig. 3. Tractor deceleration dependence on different driving speeds on hard surface road, when the highest kinematic discrepancy is $\mathbf{1 . 0 7}$ 
As it is shown in Figure 5, the tractor driving at the speed of $20 \mathrm{~km} \cdot \mathrm{h}^{-1}$ and suddenly stopping (emergency braking) on the hard surface road between $4 \times 2$ ( 1 line) and $4 \times 4$ ( 2 line) mode when having highest kinematic discrepancy of 1.07 , deceleration increased from -3.51 to $-5.76 \mathrm{~m} \cdot \mathrm{s}^{-2}$. With the minimum kinematic discrepancy of 0.997 , deceleration increased from -3.24 to $-6.84 \mathrm{~m} \mathrm{~s}^{-2}$.

The tractor braking in $4 \times 2$ mode, the average deceleration increases from -3.24 to $-3: 51 \mathrm{~m} \cdot \mathrm{s}^{-2}$. The difference of $0.27 \mathrm{~m} \cdot \mathrm{s}^{-2}$ occurs due to a better wheel grip and reduction of the pressure in the tires, so it causes no large effect on the tractor brake efficiency. However, braking on $4 \times 4$ mode, the average deceleration decreased from -5.76 to $-6.84 \mathrm{~m} \cdot \mathrm{s}^{-2}$, which is the average deceleration less by $1.08 \mathrm{~m} \cdot \mathrm{s}^{-2}$. The deceleration of the decrease can be associated with increased kinematic discrepancy between the front and rear wheels.

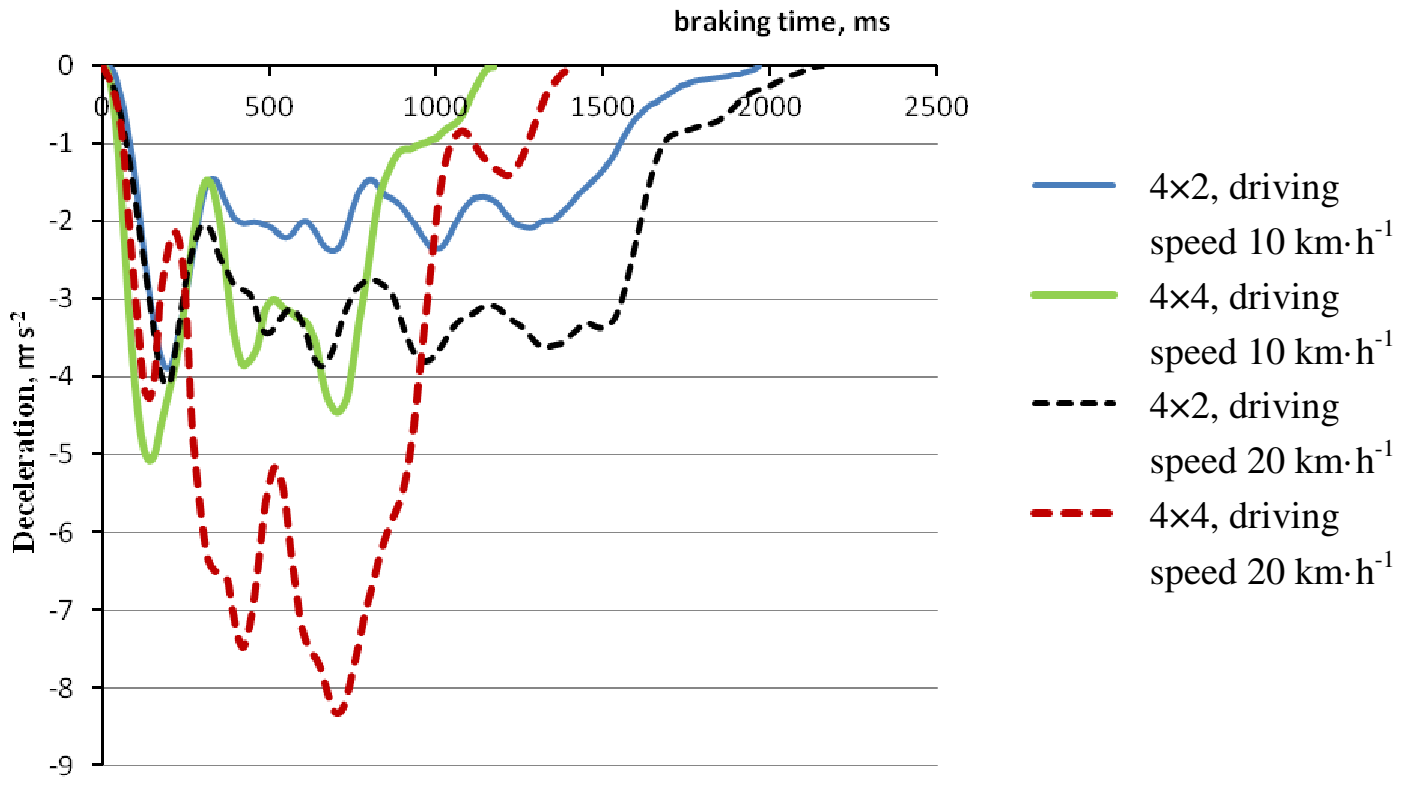

Fig. 4. Tractor deceleration dependence on different driving speeds on hard surface road, when the lowest kinematic discrepancy is 0.997

Fig. 5 shows the average deceleration of the tractor dependence of the kinematic discrepancy between the tractor drive wheels, driving at $20 \mathrm{~km} \cdot \mathrm{h}^{-1}$ and maximum braking.

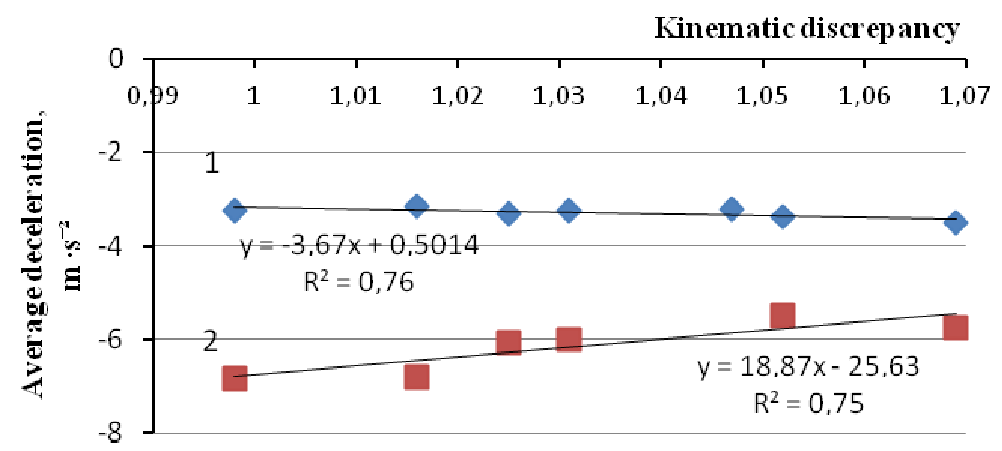

Fig. 5. Average deceleration dependence on kinematic discrepancy: 1 - travel speed of the tractor $20 \mathrm{~km} \cdot \mathrm{h}^{-1}$ in $4 \times 2$ mode; 2 - travel speed of the tractor $20 \mathrm{~km} \cdot \mathrm{h}^{-1}$ in $4 \times 4$ mode.

\section{Conclusions}

1. Tractors braking on the hard surface road between $4 \times 2$ and $4 \times 4$ mode, with the highest kinematic discrepancy 1.07, deceleration increased from -3.51 to $-5.76 \mathrm{~m} \cdot \mathrm{s}^{-2}$. With minimum kinematic discrepancy 0.997 , deceleration increased from -3.24 to $-6.84 \mathrm{~m} \cdot \mathrm{s}^{-2}$. For kinematic discrepancy the tractor deceleration difference is 2.25 and $3.6 \mathrm{~m} \cdot \mathrm{s}^{-2}$. This shows that increasing of the 
kinematic discrepancy gives not only negative effect on the tractor performance parameters, tire faster wear, increased fuel consumption, but it also reduces the tractor braking deceleration of $4 \times 4$ mode.

2. The front wheels were forced to skid because of the kinematic discrepancy, they create the opposite direction of the torque transmitted to the rear wheels, and therefore generate lower rear wheel braking torque and the total braking power. So, depending on the number of the drive wheels $(4 \times 2$ or $4 \times 4)$ the tractor stops in less time when enabling the front axle $4 \times 4$.

3. Based on this research, it can be concluded that estimation or modelling of braking efficiency of the MFWD tractor coupled with trailer or semi-trailer should include the value of the kinematic discrepancy.

\section{Reference}

1. Osinenko P.V., Geissler M., Herlitzius T. A method of optimal traction control for farm tractors with feedback of drive torque. Biosystems engineering. 129, 2015, pp. 20-33.

2. Janulevičius A., Pupinis G., Lukštas J., Damanauskas V., Kurkauskas V. Dependencies of the lead of front driving wheels on different tire deformations for a MFWD tractor, Transport. 2015; 32(1), pp. 23-31

3. Janulevičius A., Pupinis G., Kurkauskas V. How driving wheels of front-loaded tractor interact with the terrain depending on tire pressures, Journal of Terramechanics. 53, 2014, pp. 83-92.

4. Vantsevich V.V. Vehicle system dynamics: coupled and interactive dynamics analysis. Vehicle System Dynamics. 2014;51(11), pp. 1489-1516.

5. Nastasoiu M., Ispas N. Comparative analysis into the tractor-trailer braking dynamics: tractor with single axle brakes, tractor with all wheel brakes. Central European Journal of Engineering. 4(2), 2014, pp. 142-147.

6. Andreev A.F., Kabanau V., Vantsevich V. Driveline Systems of Ground Vehicles: Theory and Design (Ground Vehicle Engineering), 2010, CRC-Press.

7. Damanauskas V., Janulevičius A. Differences in tractor performance parameters between singlewheel 4WD and dual-wheel 2WD driving systems. Journal of Terramechanics, 60, 2015, pp. 63-73.

8. Ahokas J., Kosonen S. Dynamic Behaviour of a Tractor-trailer Combination during Braking. Biosystems Engineering. 85(1), 2003, pp. 29-39.

9. Taghavifar H., Mardani A. Investigating the effect of velocity, inflation pressure, and vertical load on rolling resistance of a radial ply tire. Journal of Terramechanics. 50, 2013, pp. 99-106.

10. Nastasoiu M. Study on increasing braking performance and efficiency of four-wheel-drive tractors through braking on all wheels. Proceedings of the annual session of scientific papers, IMT Oradea, 2013.

11. Nastasoiu M., Ispas N., Nastasoiu S. Study on the interaction in the tractor-attachment system during braking considering the attachment mass and the correlation of brakes control. The 8th International Conference Fuel Economy, Safety and Reliability of Motor Vehicles, ESFA 2009, Politehnica University Bucharest, ISSN - 2067-1083, 12-14 Nov. 2009.

12. Guskov V. Traktorî, vol II. Teoria. Minsk. Vîşeişaia şkola. 1977

13. Panáček V., Semela. M., Adamec, V., Schüllerová, B., 2016. Impact of usable coefficient of adhesion between tyre and road surface by modern vehicle on its dynamics while driving and braking in the curve. Transport. 31(2), 142-146.

14. General Terminology for Traction of Agricultural Traction and Transport Devices and Vehicles ANSI/ASAE S296.2. [01.03.2017]. Available at: Osinenko, P. V., Geissler, M., Herlitzius, T., 2015. A method of optimal traction control for farm tractors with feedback of drive torque. Biosystems engineering. 129, pp. 20-33. 